\title{
Recurrent ovarian mixed germ cell tumor with unusual malignant transformation: a case report
}

\author{
Yi-Le Lee ${ }^{1}$, Chiung-Ru Lai ${ }^{2,3}$ and Ming-Shyen Yen ${ }^{1,3^{*}}$
}

\begin{abstract}
Background: The value of this report is the identification of late recurrence with an extremely unusual combination of malignant transformation. In particular, the retroconversion of immature to mature teratoma as well as a somatic-type malignant transformation were both observed postchemotherapeutically in our case.

Case presentation: We report the case of a 20-year-old girl who completed fertility-sparing surgery and chemotherapy under the diagnosis of ovarian mixed germ cell tumor (immature teratoma and yolk sac tumor) and experienced subsequent recurrence 4 years after a second debulking surgery with a somatic type malignant transformation (teratoma with melanoma and leiomyosarcoma). Multiple metastases developed after a third debulking surgery, and the patient survived for 18 additional months.

Conclusions: Recurrent disease after repeated cytoreduction and chemotherapy hints a poor outcome despite a generally excellent long-term survival rate among ovarian germ cell malignancies. It is important for clinicians to distinguish those at risk of poorer outcomes and establish individualized postoperative surveillance. Fertilitycompromising surgery may be considered in selected patients.
\end{abstract}

Keywords: Ovarian mixed germ cell tumor, Chemotherapeutic retroconversion, Teratoma malignant transformation

\section{Background}

Malignant germ cell tumors account for less than 5\% of all ovarian neoplasms [1]. These lesions mostly occur in the first two decades of life, whereas immature teratomas are the second most frequent type $(20 \% \sim 35.6 \%$ of all cases) [2, 3]. For pure form tumors or a component of mixed germ cell tumors, the prognosis of immature teratomas is greatly dependent on the initial stage and histological grading, which are determined by the levels of immature neural elements that are considered to be evoluted from a malignant clone $[4,5]$. Comprehensive surgical staging is warranted. If fertility is desired, unilateral or bilateral salpingo-oophorectomy can be considered in selected patients, with every effort to confirm the extent of initial disease and achieve maximum

\footnotetext{
* Correspondence: msyen@vghtpe.gov.tw

${ }^{1}$ Department of Obstetrics and Gynecology, Taipei Veterans General Hospital and National Yang-Ming University, 201, Section 2, Shih-Pai Road, Taipei 112, Taiwan, Republic of China

${ }^{3}$ School of Medicine, National Yang-Ming University, Taipei, Taiwan Full list of author information is available at the end of the article
}

cytoreduction. Although optimal fertility-sparing cytoreduction followed by chemotherapy appears to achieve a promising outcome for women of childbearing age, refractory courses occurred in a few cases with possible mortality. A recent combined data analysis reviewing 81 adult ovarian immature teratomas revealed a relapse rate of $0,3.7$, and $20 \%$ in cases graded 1,2 , and 3, respectively [6]. Among grade 3 disease, the 5 -year event-free survival rate decreased from $91 \%$ in stage I/II to $65 \%$ in stage III/IV. Those with incomplete resection exhibited the worst outcomes. Most cases of recurrence developed within 2 years after primary therapy [7-11].

When germ cell tumors are comprised of mixed subtypes, an advanced challenge in diagnosis and treatment is noted. Mixed germ cell tumors represent only less than $1 \%$ in all ovarian germ cell tumors, in contrast to the testis, in which its proportion is up to 33\% [12]. Smith HO analyzed 1262 cases of malignant germ cell tumors and reported a lowest overall survival rate (67.4\%, compared with $89.1 \%$ in dysgerminomas and $84.0 \%$ in immature teratomas) in the group of mixed 
germ cell tumors during a median follow-up of 126 months [2]. The combination with a yolk sac tumor, which is also known as an endodermal sinus tumor, implies a more aggressive tendency [13]. The current literature suggests a beneficial role of salvage treatment in chemorefractory patients, including patients undergoing repeated surgery and second-line chemotherapy $[11,14]$. Prompt awareness of tumor marker elevation and immunochemistry-aided diagnosis were reinforced by recent studies $[2,15,16]$.

\section{Case presentation}

A 16-year-old girl was referred to our service from another hospital for further management of recurrent germ cell malignancy. Her initial presentation was abdominal bloating with an adnexal 18-cm mass and tumor marker elevation (Alpha-fetoprotein (AFP): 131.53 (0-20) ng/ $\mathrm{mL}, \mathrm{CA}$ 125: $521(0-35) \mathrm{U} / \mathrm{mL}$, Lactate dehydrogenase (LDH): 242 (98-192) IU/L). She received optimally debulked fertility-sparing staging surgery (unilateral salpingo-oophorectomy, unilateral pelvic and para-aortic lymph node dissection, omentectomy, and cul-de-sac tumor excision) followed by chemotherapy with 4 cycles of BEP (bleomycin, etoposide, and cisplatin) at age 14. Final pathology reported a mixed germ cell tumor composed of mainly immature teratoma (grade 3, FIGO stage IIIC, pT3cNOM0) with components of embryonal carcinoma (23\%) and yolk sac tumor (3\%).

During follow-up, disease recurrence was suspected due to tumor marker elevation (AFP: $118.82 \mathrm{ng} / \mathrm{mL}$, CA 125: $58.82 \mathrm{U} / \mathrm{mL}$ ) and pelvic cystic lesions with ascites on abdominal computed tomography (CT) scan. Thus, she was referred to our hospital and received second fertility-sparing debulking surgery. Intra-operative findings were a $6 \times 5-\mathrm{cm}$ solid tumor at omentum, another gray tan soft tissue measuring $5 \times 3 \mathrm{~cm}$ upon bladder, and some small cul-de-sac tumors. No residual disease was noted. All lesions were reported to be metastatic mixed germ cell tumors, which was mainly composed of an immature teratoma with focal areas of yolk sac tumors. The teratoma component is composed of squamous epithelium, intestinal-type epithelium, respiratory epithelium, mesenchymal tissue and neuroglial tissue. The immature element is found focally and is composed of fetal-type epithelium and mesenchymal tissue. This neuroglial tissue is characterized by GFAP (glial fibrillary acidic protein)-positive astrocytic cells and scattered ganglion cells. Adjuvant chemotherapy with 4 cycles of EP (etoposide and cisplatin) was completed uneventfully.

However, 4 years later (at age 20), the magnetic resonance imaging (MRI) detected an $8 \times 7-\mathrm{cm}$ cystic mass at the right adnexa with suspicious pelvic tumor seedings (Fig. 1). AFP was $42.31 \mathrm{ng} / \mathrm{mL}$, and CA 125 was $13.5 \mathrm{U} /$ $\mathrm{mL}$. The patient underwent a third conservative debulking surgery with excision of a right ovarian cystic lesion and pelvic tumors. The surgery was considered optimal, but some residual tumors remained in the cul-de-sac, all of which were less than $10 \mathrm{~mm}$ in diameter. The pathology results of the right ovarian tumor suggested a teratoma and associated mucinous cystadenoma, whereas the intrapelvic tissue sections revealed a mixed germ cell tumor composed of teratoma with somatic type malignancy (melanoma and leiomyosarcoma) and foci of yolk sac tumor (Figs. 2 and 3). No immature component is identified within the teratoma. Pelvic recurrence and multiple metastases were noted 8 months later after a third debulking surgery. Biopsy of sacral bone, lung, and liver were compatible with the presence of sarcomatous cells. The patient received palliative radiotherapy, salvage chemotherapy with high-dose doxorubicin and ifosfamide
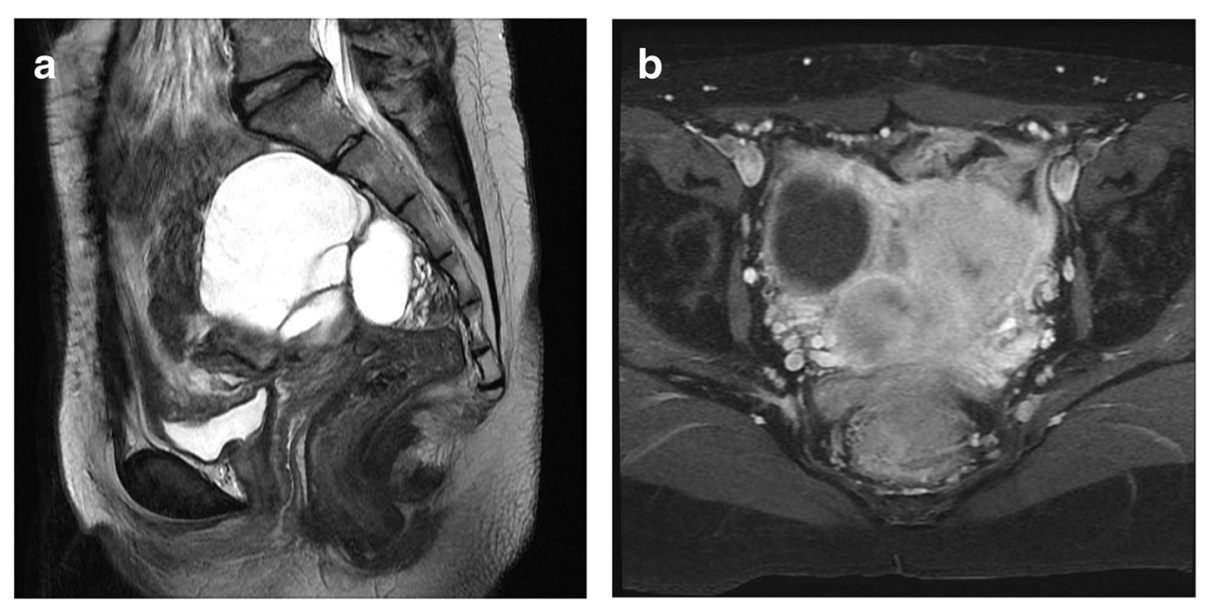

Fig. $1 \mathrm{MRI}$ T2-weighted images of pelvic cavity. a Sagittal view showing a 7.8 $\times 7.3-\mathrm{cm}$ cystic mass with internal septa and blood content at right adnexa. b Axial view showing some enhancing soft tissue at the cul-de-sac with restricted diffusion on diffusion-weighted imaging, in favor of tumor seedings 


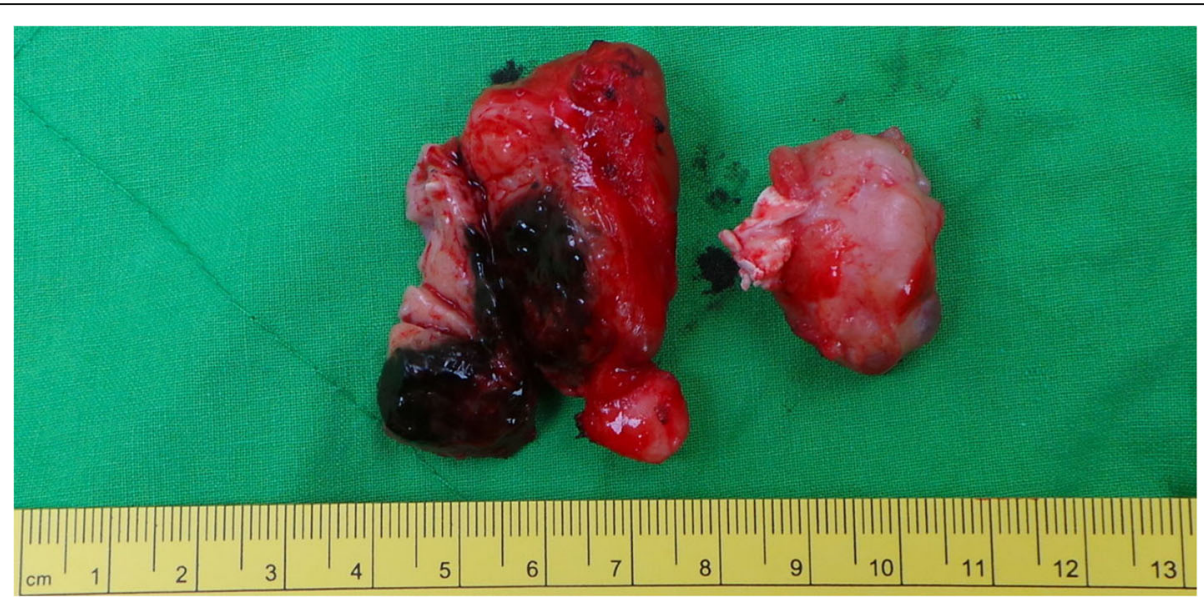

Fig. 2 Gross finding of intra-pelvic tissue. Two pieces of tan soft to firm tissue were labeled as tumors on the bladder surface measuring $5 \times 3 \times$ $3 \mathrm{~cm}$ and $3.2 \times 2.5 \times 1.6 \mathrm{~cm}$. Dark pigmentation is noted within the $5-\mathrm{cm}$ tissue

for leiomyosarcoma, and immunotherapy with pembrolizumab for melanoma. She died of disease 10 months later.

\section{Discussion}

It is known that immature teratomas are associated with mature teratomas. Approximately $26 \%$ of synchronous typical mature teratomas were detected in cases of immature teratomas, including contralateral ovary (approximately $40 \%$ of teratomas) [17]. The concept behind the scene is that ovarian teratomas originate from benign germ cells, whereas the evolution of a malignant clone results in its immature elements, which affect the
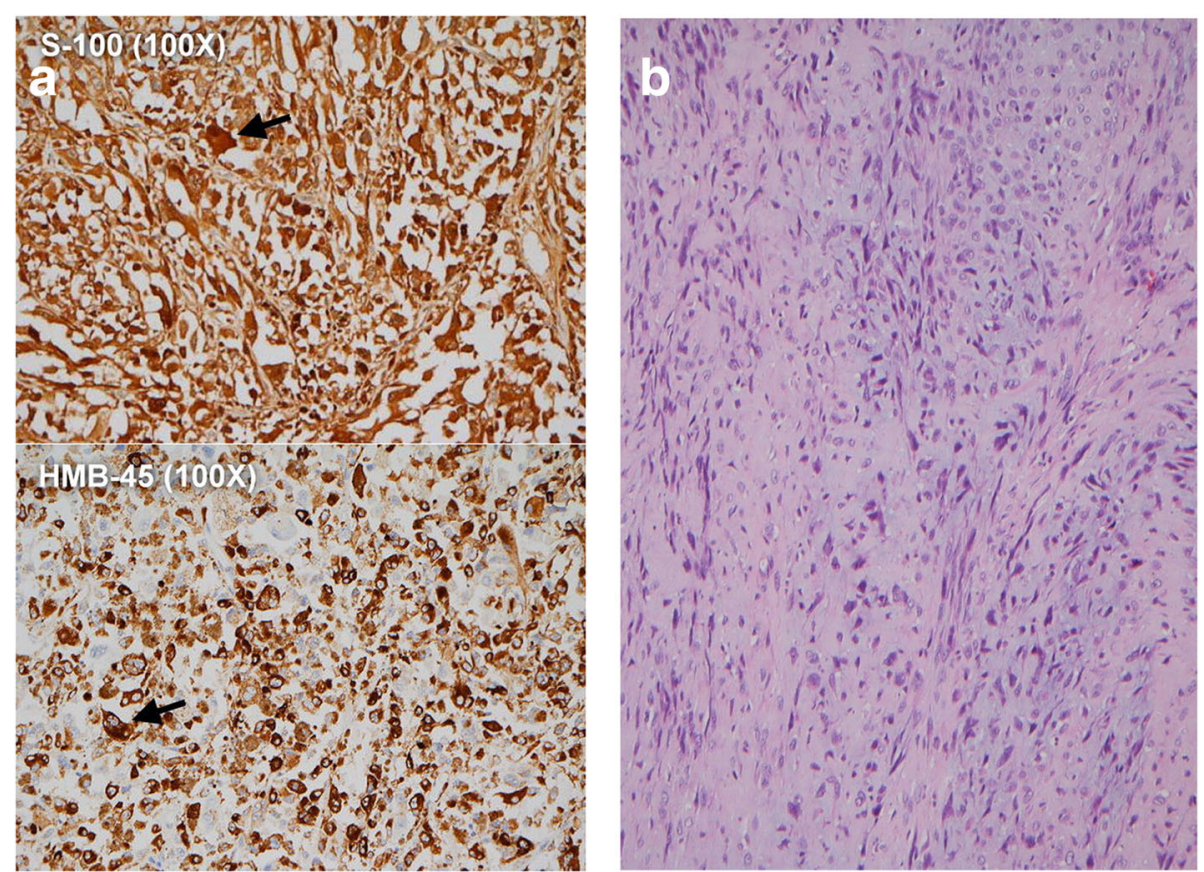

Fig. 3 Histological examination of surgical specimen. Sections of the bladder tumor reveal a mixed germ cell tumor that is mainly composed of a teratoma with somatic-type malignancy (melanoma and leiomyosarcoma). No immature component is identified. The yolk sac tumor component is only observed in focal areas. The melanoma is composed of sheets of neoplastic cells with melanin pigment, which is demonstrated with Fontana-Masson stain. The melanoma tumor cells are immuno-reactive for S-100, Melan A and HMB-45. The leiomyosarcoma cells are positive for SMA and HHF-35 but nonreactive for h-Caldesmon. a Sheets of melanoma cells with melanin pigment (original magnifications X100). Positive staining for S-100 is noted in both the nuclei and cytoplasm of cells, and the cytoplasm is positive for HMB-45. b Hematoxylin and eosin-stained sections (original magnifications X100) reveal spindle-shaped tumor cells with marked nuclear atypia and frequent mitotic figures (> 10/10 hpf) compatible with leiomyosarcoma (positive for SMA and HHF-35) 
prognosis most [12]. Occasionally, microfoci of immature tissue $\left(<21 \mathrm{~mm}^{3}\right)$ may present simultaneously in mature teratomas without clinical significance [17]. An improved survival rate via so-called chemotherapeutic retroconversion was recognized among immature teratomas $[18,19]$. Through the phenomenon undergoing tissue maturation, a distinct role and favorable outcomes of salvage treatment in immature teratomas are noted compared with other ovarian malignant germ cell tumor types [14, 20]. A similar phenomenon, namely, growing teratoma syndrome, was significantly reported in males with testicular nonseminomatous tumors. Only 101 cases were listed in a literature review of ovarian growing teratoma syndrome with highlights on persistent mass lesions with normalization of serum tumor markers [21, 22]. Either differentiation of malignant cells into mature elements or a chemotherapy effect was thought to be the possible mechanism.

On the other hand, malignant transformation of mature teratoma is uncommon, occurring in $0.19-2 \%$ of dermoid cysts in patients often greater than 60 years of ages [23]. These lesions are generally an adult type malignancy in contrast to an immature teratoma that is most commonly a squamous cell carcinoma (80\%), and a variety of cell types, including carcinoid, adenocarcinoma, thyroid and basal cell carcinoma, melanoma, and sarcoma, are noted [24]. In particular, a high rate of histopathological aneuploidy and malignant potential were noted in teratoma components that underwent chemotherapeutic retroconversion in the cases of nonseminomatous testicular tumor with secondary malignancy [25-27]. Complete resections often reproduce favoring curative results. Among ovarian dermoid-associated malignancies, a worse prognosis is noted for melanomas (greater than half of deaths occurred within 18 months) $[28,29]$. Primary ovarian melanoma is rare with approximately 50 cases to date, [29] and the diagnosis is more convincing with unilaterality, junctional change, and exclusion of another primary site [30]. Various adjuvant chemotherapies and immunotherapies with biologic agents have been used given the poor outcomes that are even worse than cutaneous melanoma [31].

An ongoing debate exists regarding how teratomatous elements develop in mixed germ cell tumors. Current histogenetic analysis hypothesized that the presence of isochromosome $12 \mathrm{p}(\mathrm{i}(12 \mathrm{p}))$ and $12 \mathrm{p}$ amplification in mixed germ cell tumors as well as their absence in pure form teratomas (whether mature or immature) supported its derivation from its nonteratomatous components rather than a parthenogenetic origin of a nontransformed germ cell [32].

In the outcome analysis of 20 cases with malignant ovarian germ cell tumors after salvage surgery from Munkarah A et al., [20] a third debulking surgery was reported in only two out of eight immature teratoma patients with greater than 15-year remission in both cases (186 and 202 months respectively). Rezk Y et al. reported a case similar as ours [18] with a grade 3 immature teratoma with foci of yolk sac tumor who failed two different regimens of platinum-based chemotherapy. The patient remained disease-free greater than 4 years after secondary debulking surgery. The value of this report is the identification of late recurrence with an extremely unusual combination of malignant transformation. The disease relapsed 2 years after primary treatment and again 4 years after salvage therapy, which is longer than generally expected. With advanced initial histology grade and stage, the disease exhibited an aggressive behavior with refractory courses and distant metastases despite a second round of chemotherapy and third debulking surgery. Interestingly, the retroconversion of an immature to mature teratoma as well as somatic-type malignant transformation were both observed postchemotherapeutically in our case, which added to the disease complexity.

Post-treatment surveillance in recurrent female germ cell tumors is not yet well-established. Given the sensitivity of serum markers in disease detection and the concern of radiation, the Society of Gynecologic Oncologists recommended that imaging is not indicated before laboratory or clinical findings [33].

Some novel therapies were proposed for platinum-resistant and multiply relapsed germ cell tumors, mainly in male patients [34]. High-dose chemotherapy plus hematopoietic stem cell rescue was potentially effective in progressively growing testicular cancer [35]. Attempts on target agents, such as sunitinib and bevacizumab, were made based on the role of vascular endothelial growth factor in metastatic germ cell tumors [36, 37]. The pathogenesis of germ cell tumors appears different from other somatic tumors with much less involvement of mutations in those common oncogenes or tumor suppressor genes [38]. Whole-genome sequencing may help determine the complicated features of malignant ovarian germ cell tumors provide important information for personalized medicine.

\section{Conclusions}

Given the generally chemo-sensitive feature and reproductive needs of these patients, optimal cytoreduction is warranted to achieve a maximum benefit from subsequent chemotherapy. Although long-term survival rate is excellent among ovarian germ cell malignancies under current treatment strategies, relapsing disease after chemotherapy indicates a poor prognosis especially in cases with higher grades and stages. Post-treatment recurrence may have late presentation despite a stable period after salvage therapy, whereas the retroconversion and somatic-type malignant transformation both existed. 
To the best of our knowledge, it is the first report of ovarian mixed germ cell tumor with both these two phenomenon observed at the same time. We propose that curative surgery that compromises fertility should be considered in these patients with advanced and relapsing disease. Given the rarity of the disease, it is important for clinicians to distinguish those at risk of poorer outcomes and establish individualized postoperative surveillance before the presence of more valid evidence-based guidance. Novel therapeutic agents are under investigation and expected to deliver promising results.

\section{Abbreviations}

AFP: Alpha-fetoprotein; BEP: bleomycin, etoposide, and cisplatin; CT: computed tomography; EP: etoposide and cisplatin; HCG: human chorionic gonadotropin; MRI: magnetic resonance imaging

\section{Acknowledgements}

Not applicable.

\section{Availability of data and materials}

The datasets used during the current study are available from the corresponding author on reasonable request.

\section{Authors' contributions}

YLL collected the clinical data and performed the manual microdissection. MSY and CRL drafted the manuscript, including the revision. YLL and MSY participated in the treatment and reviewed the manuscript. YLL, MSY and CRL performed the pathological diagnosis and immunohistochemical staining. All authors read and approved the final manuscript.

\section{Ethics approval and consent to participate}

This work has been approved by the ethics committee of Taipei Veterans General Hospital, and informed consent for publication was obtained from the patient.

\section{Consent for publication}

Written informed consent was obtained from the patient and publication of this report and accompanying images. A copy of this written consent is available for review by the Editor-in Chief of this journal.

\section{Competing interests}

The authors declare that they have no competing interests.

\section{Publisher's Note}

Springer Nature remains neutral with regard to jurisdictional claims in published maps and institutional affiliations.

\section{Author details}

'Department of Obstetrics and Gynecology, Taipei Veterans General Hospital and National Yang-Ming University, 201, Section 2, Shih-Pai Road, Taipei 112, Taiwan, Republic of China. ${ }^{2}$ Department of Pathology and Laboratory Medicine, Taipei Veterans General Hospital, Taipei, Taiwan. ${ }^{3}$ School of Medicine, National Yang-Ming University, Taipei, Taiwan.

Received: 22 October 2018 Accepted: 13 December 2018

Published online: 10 January 2019

\section{References}

1. Gershenson DM, Del Junco G, Copeland L, Rutledge FN. Mixed germ cell tumors of the ovary. Obstet Gynecol. 1984;64(2):200-6.

2. Smith $\mathrm{HO}$, Berwick $M$, Verschraegen $C F$, Wiggins $C$, Lansing $L$, Muller $C Y$, et al. Incidence and survival rates for female malignant germ cell tumors. Obstet Gynecol. 2006:107(5):1075-85.

3. Burkman RT. Berek \& Novak's gynecology. JAMA. 2012;308(5):516-7.
4. O'Connor DM, Norris HJ. The influence of grade on the outcome of stage I ovarian immature (malignant) teratomas and the reproducibility of grading. Int j Gynecol Pathol. 1994;13(4):283-9.

5. Norris HJ, Zirkin HJ, Benson WL. Immature (malignant) teratoma of the ovary: a clinical and pathologic study of 58 cases. Cancer. 1976;37(5):2359-72.

6. Erratum, Pashankar F, Hale JP, Dang H, et al. Is adjuvant chemotherapy indicated in ovarian immature teratomas? A combined data analysis from the Malignant Germ Cell Tumor International Collaborative. Cancer. 2016; 122:230-7 Cancer. 2018;124(6):1302.

7. Vicus D, Beiner ME, Clarke B, Klachook S, Le LW, Laframboise S, et al. Ovarian immature teratoma: treatment and outcome in a single institutional cohort. Gynecol Oncol. 2011;123(1):50-3.

8. Pectasides D, Pectasides E, Kassanos D. Germ cell tumors of the ovary. Cancer Treat Rev. 2008;34(5):427-41.

9. Gershenson DM. Management of ovarian germ cell tumors. J Clin Oncol. 2007;25(20):2938-43

10. Murugaesu N, Schmid P, Dancey G, Agarwal R, Holden L, McNeish I, et al. Malignant ovarian germ cell tumors: identification of novel prognostic markers and long-term outcome after multimodality treatment. J Clin Oncol. 2006;24(30):4862-6.

11. Patterson DM, Rustin GJ. Controversies in the management of germ cell tumours of the ovary. Curr Opin Oncol. 2006;18(5):500-6.

12. Ulbright TM. Germ cell tumors of the gonads: a selective review emphasizing problems in differential diagnosis, newly appreciated, and controversial issues. Mod Pathol. 2005;18(Suppl 2):S61-79.

13. Woodruff JD, Protos P, Peterson WF. Ovarian teratomas. Relationship of histologic and ontogenic factors to prognosis. Am J Obstet Gynecol. 1968. 102(5):702-15.

14. Li J, Yang W, Wu X. Prognostic factors and role of salvage surgery in chemorefractory ovarian germ cell malignancies: a study in Chinese patients. Gynecol Oncol. 2007;105(3):769-75

15. Bouquet de Joliniere J, Ben Ali N, Fadhlaoui A, Dubuisson JB, Guillou L, Sutter A, et al. Two case reports of a malignant germ cell tumor of ovary and a granulosa cell tumor: interest of tumoral immunochemistry in the identification and management. Front Oncol. 2014;4:97

16. Matei D, Brown J, Frazier L. Updates in the management of ovarian germ cell tumors. Am Soc Clin Oncol Educ Book. 2013:e210-e216.

17. Yanai-Inbar I, Scully RE. Relation of ovarian dermoid cysts and immature teratomas: an analysis of 350 cases of immature teratoma and 10 cases of dermoid cyst with microscopic foci of immature tissue. Int J Gynecol Pathol. 1987;6(3):203-12.

18. Rezk Y, Sheinfeld J, Chi DS. Prolonged survival following salvage surgery for chemorefractory ovarian immature teratoma: a case report and review of the literature. Gynecol Oncol. 2005;96(3):883-7.

19. DiSaia PJ, Saltz A, Kagan AR, Morrow CP. Chemotherapeutic retroconversion of immature teratoma of the ovary. Obstet Gynecol. 1977;49(3):346-50.

20. Munkarah A, Gershenson DM, Levenback C, Silva EG, Messing MJ, Morris M, et al. Salvage surgery for chemorefractory ovarian germ cell tumors. Gynecol Oncol. 1994:55(2):217-23.

21. David YB, Weiss A, Shechtman L, Shalev E. Tumor chemoconversion following surgery, chemotherapy, and normalization of serum tumor markers in a woman with a mixed type germ cell ovarian tumor. Gynecol Oncol. 2002:84(3):464-7.

22. Li S, Liu Z, Dong C, Long F, Liu Q, Sun D, et al. Growing Teratoma syndrome secondary to ovarian Giant immature Teratoma in an adolescent girl: a case report and literature review. Medicine. 2016;95(7):e2647.

23. Comerci JT Jr, Licciardi F, Bergh PA, Gregori C, Breen JL. Mature cystic teratoma: a clinicopathologic evaluation of 517 cases and review of the literature. Obstet Gynecol. 1994;84(1):22-8.

24. Hackethal A, Brueggmann D, Bohlmann MK, Franke FE, Tinneberg HR, Munstedt K. Squamous-cell carcinoma in mature cystic teratoma of the ovary: systematic review and analysis of published data. Lancet Oncol. 2008 ; 9(12):1173-80

25. Davey DD, Ulbright TM, Loehrer PJ, Einhorn LH, Donohue JP, Williams SD. The significance of atypia within teratomatous metastases after chemotherapy for malignant germ cell tumors. Cancer. 1987:59(3):533-9.

26. Castedo SM, de Jong B, Oosterhuis JW, Idenburg VJ, Seruca R, Buist J, et al. Chromosomal changes in mature residual teratomas following polychemotherapy. Cancer Res. 1989;49(3):672-6.

27. Molenaar WM, Oosterhuis JW, Meiring A, Sleyfer DT, Schraffordt Koops H, Cornelisse CJ. Histology and DNA contents of a secondary malignancy 
arising in a mature residual lesion six years after chemotherapy for a disseminated nonseminomatous testicular tumor. Cancer. 1986;58(2):264-8.

28. Davis GL. Malignant melanoma arising in mature ovarian cystic teratoma (dermoid cyst). Report of two cases and literature analysis. Int J Gynecol Pathol. 1996;15(4):356-62.

29. Narendra H, Manilal B, Revanth G, Praveen CS, Radhika K, Asha T. Metastasizing primary malignant melanoma of the ovary: a diagnostic enigma. J Gynecol Surg. 2015;31(3):166-72.

30. Cronje HS, Woodruff JD. Primary ovarian malignant melanoma arising in cystic teratoma. Gynecol Oncol. 1981;12(3):379-83.

31. Hyun HS, Mun ST. Primary malignant melanoma arising in a cystic teratoma. Obstet Gynecol Sci. 2013;56(3):201-4.

32. Poulos C, Cheng L, Zhang S, Gersell DJ, Ulbright TM. Analysis of ovarian teratomas for isochromosome 12p: evidence supporting a dual histogenetic pathway for teratomatous elements. Mod Pathol. 2006;19(6):766-71.

33. Salani R, Backes FJ, Fung MF, Holschneider CH, Parker LP, Bristow RE, et al. Posttreatment surveillance and diagnosis of recurrence in women with gynecologic malignancies: Society of Gynecologic Oncologists recommendations. Am J Obstet Gynecol. 2011;204(6):466-78.

34. Vazquez I, Rustin GJ. Current controversies in the management of germ cell ovarian tumours. Curr Opin Oncol. 2013;25(5):539-45.

35. Einhorn LH, Williams SD, Chamness A, Brames MJ, Perkins SM, Abonour R. High-dose chemotherapy and stem-cell rescue for metastatic germ-cell tumors. N Engl J Med. 2007:357(4):340-8.

36. Richie JP. Preclinical and clinical activity of sunitinib in patients with cisplatin-refractory or multiply relapsed germ cell tumors: a Canadian urologic oncology group/German testicular cancer study group cooperative study. J Urol. 2013;189(2):533-4

37. Jain A, Brames MJ, Vaughn DJ, Einhorn LH. Phase II clinical trial of oxaliplatin and bevacizumab in refractory germ cell tumors. Am J Clin Oncol. 2014; 37(5):450-3.

38. Kraggerud SM, Hoei-Hansen CE, Alagaratnam S, Skotheim Rl, Abeler VM, Rajpert-De Meyts E, et al. Molecular characteristics of malignant ovarian germ cell tumors and comparison with testicular counterparts: implications for pathogenesis. Endocr Rev. 2013:34(3):339-76.

Ready to submit your research? Choose BMC and benefit from:

- fast, convenient online submission

- thorough peer review by experienced researchers in your field

- rapid publication on acceptance

- support for research data, including large and complex data types

- gold Open Access which fosters wider collaboration and increased citations

- maximum visibility for your research: over $100 \mathrm{M}$ website views per year

At $\mathrm{BMC}$, research is always in progress.

Learn more biomedcentral.com/submissions 